\title{
Prefixos relacionais em Kaiowá
}

\author{
Andérbio Márcio Silva Martins ${ }^{1}$ \\ Ana Suelly Arruda Câmara Cabral ${ }^{2}$ \\ Blanca Flor Demenjour Munoz Mejia ${ }^{3}$ \\ Lívia Ribeiro Viegas ${ }^{4}$
}

\begin{abstract}
Resumo
Descrevemos a funcionalidade dos prefixos relacionais da língua Kaiowá, membro do sub-ramo I da família linguística Tupí-Guaraní (cf. Rodrigues, 1985). De acordo com Rodrigues (1981, 1985, 1996) e Cabral (2001), trata-se de morfemas que marcam relações de dependência (subordinação e determinação) e de contiguidade sintática entre temas relativos (verbos, posposicições e parte dos temas nominais) e seus respectivos determinante. Em Kaiowá, identificamos quatro prefixos relacionais: $\mathrm{R}^{1}$ (marca de contiguidade sintática do determinante em relação ao determinado); $\mathrm{R}^{2}$ (marca de não-contiguidade sintática do determinante em relação ao tema determinado); $\mathrm{R}^{3}$ (marca de correferencialidade com $\mathrm{o}$ sujeito de terceira pessoa); e $\mathrm{R}^{4}$ (marca no determinado que o seu determinante é genérico humano). Demonstramos que, embora os relacionaisda língua Kaiowá tenham sofrido mudanças na história da língua, as quais ocasionaram deslocamentos de temas de uma classe a outra, continuam ativos e fundamentais na morfossintaxe Kaiowá.
\end{abstract}

Palavras-chave: Prefixos Relacionais; Língua Kaiowá; Família Tupí-Guaraní.

\begin{abstract}
We describe the functionality of the relational prefixes found in the Kaiowá language, a member of sub-branch I of the Tupí-Guaraní family (Rodrigues, 1985). According to Rodrigues (1981, 1985, 1996) and Cabral (2001), relational prefixes mark relations of dependency, as well as syntactic contiguity (contiguous/noncontiguous) between a relative stem (verbal, postpositional and part of the nominal themes) and its determiner. In Kaiowá, four relational prefixes are identified: R1 (marks the syntactic contiguity of the determiner), R2 (marks the syntactic non-contiguity of determiner); R3 (marks the co-referentiality holding between the determiner and a third person subject), and R4 (marks a generic and human determiner). We demonstrate that, although the distribution of relational prefixes had suffered historical changes, moving stems away from their original classes, they remain active and fundamental to Kaiowá morphosyntax.
\end{abstract}

Keywords: Relational Prefixes, Kaiowá language, Tupí-Guaraní family.

\footnotetext{
${ }^{1}$ Doutor em Linguística e Professor do Programa de Pós-Graduação em Letras da Faculdade de Comunicação, Artes e Letras da Universidade Federal da Grande Dourados (PPG Letras/ FACALE/UFGD). E-mail: anderbiomartins@ufgd.edu.br.

${ }^{2}$ Doutora em Linguística e Professora do Programa de Pós-Graduação em Linguística da Universidade de Brasília. E-mail: asacczoe@gmail.com. Bolsista em Produtividade Científica PQ1C/CNPq.

${ }^{3}$ Mestra em Letras pelo PPG Letras/FACALE/UFGD. E-mail: blancaflor_ufgd@hotmail.com.

${ }^{4}$ Mestra em Letras pelo PPG Letras/FACALE/UFGD. E-mail: liviarviegas@hotmail.com.
} 


\section{Considerações iniciais}

Os povos Kaiowá e Guarani-Nhandéva ${ }^{5}$, no Brasil, estão localizados ao sul do estado de Mato Grosso do Sul. Somam, segundo o IBGE, uma população de cerca de 51.801 indivíduos, dentre os quais 38.525 teriam vivido nas 8 reservas indígenas criadas pelo SPI, no período entre 1915 e 1928, 10.646 nas 22 terras indígenas demarcadas após 1980 e 2.630 em 25 acampamentos (Cavalcante, 2013, p. 84). ${ }^{6}$

Somente a partir dos movimentos de luta por demarcação de terras na década de 1970, o Estado passa a considerar a possibilidade de identificar e delimitar terras para os Guarani e Kaiowá, o que é feito a partir da década de 1980. Até o momento presente, são 22 áreas identificadas e delimitadas, mas apenas 12 estão completamente sob a posse dos indígenas. Cavalcante (2013, p. 104) informa que apenas $22,02 \%$ das áreas reconhecidas após 1980 estão na posse dos Guarani e Kaiowá, pois somente 30.415 ha dos 138.096 ha permanecem sob o domínio indígena, os $77,98 \%$ restantes continuam sendo apenas terras de papel. E mesmo nesse contexto de luta dos contínua dos Kaiowá por terra, além de pressionados por intenso e contínuo contato com o Português e outras línguas indígenas, a sua língua nativa tem resistido, mantendo características fonológicas, morfológicas e sintáticas conservadoras, não mais encontradas nas outras línguas irmãs do subramo I da família linguística Tupí-Guaraní.

A língua Kaiowá foi classificado por Rodrigues (1984/1985) como um dos membros do sub-ramo I da família Tupí-Guaraní, do qual fazem parte também o Guaraní Antigo, o Nhandéva, o Guarani Paraguaio, o Xetá (Serra dos Dourados), o Mbyá, o Chiriguano (Ava), o Tapieté, o Isoceño (Chané) e o Guayakí (Aché)7.

\footnotetext{
${ }^{5}$ Os Guarani-Nhandéva do sul do estado de Mato Grosso do Sul se autodenominam Guaraní, o mesmo nome atribuido a sua língua nativa. Muitas vezes, o termo Guarani é utilizado no sentido mais genérico, no qual é incluído também os Kaiowá. Essa generalização é muito comum na mídia local e por parte da população que desconhece ou ignora as diferenças linguísticas, culturais, históricas e territoriais entre os dois povos. De acordo com o Censo do IBGE, a população Kaiowá do estado de MS é de 43.400 indivíduos, dos quais 35.300 vivem em terras indígenas e 8.100 fora delas.

${ }^{6}$ As reservas indígenas criadas pelo SPI durante o período de 1915 a 1928 são as seguintes: Amambai, Dourados, Caarapó, Porto Lindo, Taquaperi, Sassoró, Limão Verde e Pirajuí. Dessas, seis estão localizadas em áreas consideradas tradicionalmente Kaiowá (Amambai, Dourados, Caarapó, Taquaperi, Sassoró e Limão Verde) e duas localizadas em áreas consideradas tradicionalmente Guarani (Porto Lindo e Pirajuí). No entanto, nas reservas Kaiowá, há a presença de pessoas Guarani, sobretudo na Reserva de Dourados, que é composta de duas aldeias (Jaguapiru e Bororó), nais quais, têm vivido, desde 1917, além de Kaiowá e Guarani, uma expressiva população Terena, configurando-se quase cem anos de contato entre indígenas de diferentes etnias nessa Reserva (Pereira, 2015).

${ }^{7}$ As características mais gerais identificadas por Rodrigues nas línguas que compõem o sub-ramo I da família Tupí-Guaraní e que fundamentaram a sua proposta de classificação interna dessa família são as seguintes: perdas das consoantes finais; conservação de *t $\int$
} 
Os primeiros estudos linguísticos sobre a língua Kaiowá foram relizados com vistas à catequização dos indígenas por linguistas do Sumer Institute of linguistics atuantes na Missão Caiuá ${ }^{8}$, e datam do final da década de 1950. Esses linguistas elaboraram a primeira proposta de escrita prática para a língua Kaiowá, com base nas análises fonológicas preliminares de Bridgeman (1960, 1961), de Harrison \& Taylor $(1958,1971)$ e de estudos gramaticais realizados pelo casal John Michael Taylor e Audrey Helen Taylor (1966). ${ }^{9}$

Com o objetivo de facilitar o aprendizado da língua Kaiowá por outros missionários que viriam a trabalhar com o povo, produziram estudos com finalidade pedagógica como a "Gramática Pedagógica da Língua Kaiuá" (J. Taylor e A. Taylor, s/d) e "Dicas sobre a língua Kaiowá" (Bridgeman, 2001). Outros estudos existentes sobre a língua Kaiowá são de autoria de Cardoso (2005a, 2005b, 2006, 2007, 2008, 2009, 2010a, 2010b, 2012, 2014a , , 2010c, 2011, 2013, 2014b, 2014c, 2014d), Silva (2014), e Martins (2014).

Mesmo com esses estudos já realizados, há vários aspectos da língua que precisam ser aprofundados, tanto em perspectiva sincrônica quanto diacrônica. Em uma perspectiva sincrônica, descrevemos, neste artigo, uma das características gramaticais do Kaiowá, típica das línguas Tupí-Guaraní, que não teve atenção especial nos trabalhos já realizados sobre essa línga. Trata-se dos prefixos relacionais.

Descrevemos, assim, a funcionalidade dos prefixos relacionais existentes na língua Kaiowá, fundamentando nosso estudo em Rodrigues $(1981,1996)$ e Cabral (2001). De acordo com esses autores, esses morfemas marcam relações de dependência (subordinação e determinação) nos temas dependentes ou relativos (temas verbais, posposicionais e parte dos temas nominais), assim como a contiguidade sintática (contíguo e não contíguo) dos seus respectivos determinantes.

Em Kaiowá, identificamos quatro prefixos relacionais, em concordância com as línguas Tupí-Guraní conservadoras: $\mathrm{R}^{1}$ (marca de contiguidade sintática do determinante em relação ao determinado); $\mathrm{R}^{2}$ (marca de nãocontiguidade sintática do determinante em relação ao tema determinado); $\mathrm{R}^{3}$ (marca de correferencialidade com o sujeito de terceira pessoa); e $\mathrm{R}^{4}$ (marca

ou sua mudança em ts ou s; mudança de *ts em h ou zero; mudança de *pw em kw ou k; mudança de * $\mathrm{p}^{\mathrm{j}}$ em $\mathrm{t} \int$ ou $\int$ (Rodrigues, 1984/1985).

${ }^{8}$ A Missão Caiuá atua na Reserva Indígena de Dourados desde 1928, sendo a primeira instituição não governamental a desenvolver atividades de modo contínuo nessa área (internato, hospital, escola, templos e espaços destinados à prestação de diversos serviços de atendimento aos indígenas), conforme Pereira (2015, p. 782).

${ }^{9}$ Em 1986 os missionários traduziram Novo Testamento para a língua Kaiowá e a Bíblia, em 2013. Outros (1981), discorreu sobre a estrutura de discursos orais de diversas situações discursivas (doutrinários, instrucionais e conversacionais), e Taylor produz dois estudos, sobre a marcação temporal na língua (1984a,) e sobre a interrogação (1984b). 
no determinado que o seu determinante é genérico humano). Mostramos que, embora os relacionais dessa língua tenham sofrido erosões em certos contextos morfossintáticos, ocasionando mudanças de classes de vários temas, continuam ativos e fundamentais na morfossintaxe da língua.

\section{Flexão relacional: breves apontamentos ${ }^{10}$}

Trabalhos esclarecedores do que são prefixos relacionais, que funções exercem, que formas possuem, quantos são, e quais línguas os possuem são de autoria de Rodrigues $(1981,1996)$ e de Cabral (2001).

Rodrigues (1981), na descrição das estruturas do Tupinambá, chama de prefixos relacionais um conjunto de morfemas que estabelece relações de dependência e contiguidade sintática entre termos ou expressões determinantes e os núcleos por estes determinados ${ }^{11}$.

Cabral (2001) ressalta que nos primeiros estudos de línguas Tupí-Guaraní já haviam sido identificadas mudanças que ocorriam no início de nomes, verbos e posposições que distinguiam as formas absolutas das formas relativas das palavras, como nas gramáticas do Tupinambá por Anchieta (1595) e Figueira (1687) e nas gramáticas do Guaraní Antigo de Montoya (1640) e Restivo (1724). No entanto, esclarece que, embora os primeiros gramáticos de línguas TupíGuaraní tenham fornecido importantes pistas para a compreensão da natureza relacional dessas marcas, é no trabalho de Rodrigues (1981) que foi oferecida uma descrição completa desses morfemas. Nesse seu estudo, Rodrigues definiu a função de cada prefixo, a alomorfia relativa a cada um deles, seu pertencimento a um mesmo paradigma flexional, e a divisão de classes morfológicas de temas em função da ocorrência destes com os alomorfes desses prefixos.

${ }_{10}$ Abreviaturas e símbolos usados: $\mathrm{ABL}=$ Ablativo; $\mathrm{ASS}=$ Associativo; $\mathrm{ATEN}=$ Atenuativo; $\mathrm{CAUS}=$ Causativo, $\mathrm{CC}=$ Causativo comitativo $; \mathrm{CPL}=$ Completivo $; \mathrm{C} . \mathrm{PREP}=$ Causativo prepositivo; DAT $=$ Dativo DIR $=$ Diretivo; D.PRON $=$ Dativo pronominal DIR $=$ Diretivo $;$ ENF = Enfático; Excl = Exclusiva $;$ EXO = exortativo; FREQ = Frequentativo; GEN = Genuíno; INESS = Inessivo; Incl = Inclusiva; INSTR = Instumentivo; LP = Locativo pontual; $\mathrm{NOM}=$ Nominalizador; N.OBJ $=$ Nominalizador de objeto; PERL = Perlativo; PERM = Permissivo; PROJ = Projetivo; REC = Recíproco; REF = Reflexivo; $\mathrm{R}^{1}$ $=$ Relacional que marca a contiguidade do determinate; $\mathrm{R}^{2}=$ Relacional que marca a não contiguidade do determinante; $\mathrm{R}^{3}=$ Relacional que marca a correferência com o sujeito do verbo da oração principal; $\mathrm{R}^{4}=$ Relacional que marca que o determinante é genérico e humano; REL = Relativo; RETR = Retrospectivo; SUBJ = Subjuntivo; 1 .incl = Priemira pessoa inclusiva; 1 excl $=$ Primeira pessoa exclusiva; $\mathrm{pl}=$ Plural; $1=$ Primeira pessoa; 2 $=$ Segunda pessoa; 3 = terceira pessoa $; \neq=$ diferente.de; $\sim=$ variação; $\infty$ = variação não condicionada fonologivcamente.

${ }^{11}$ Em outros trabalhos, Rodrigues demonstrou a existência de prefixos relacionais não apenas em línguas da família Tupí-Guaraní, mas também em línguas de outras famílias do tronco Tupí (Rodrigues, 1992, 1997, 1999), na família Karíb (1985b, 1992) e em línguas pertencentes ao tronco Macro-Jê (1992, 1999), conforme Cabral (2001, p. 233). 
Os prefixos relacionais do Tupinambá apontados por Rodrigues podem ser visualizados no quadro 1 , a seguir:

\section{Quadro 1: Prefixos Relacionais do Tupinambá (quadro extraído de Cabral 2001: 237)}

\begin{tabular}{|c|l|l|}
\hline $\mathbf{1}$ & $\mathrm{r}-\infty \varnothing-$ & $\begin{array}{l}\text { "o determinante é a expressão nominal contígua } \\
\text { (imediatamente precedente): } \mathrm{D}=\mathrm{C} ; \text {; }\end{array}$ \\
\hline $\mathbf{2}$ & $\begin{array}{l}\text { (s- } \sim \text { jos- }) \infty \mathrm{t}-\infty \\
\text { (i- } \sim \text { jo- }) \infty \varnothing-\end{array}$ & $\begin{array}{l}\text { "o determinante é diferente do sujeito e distinto do falante e } \\
\text { do ouvinte: } \mathrm{D} \neq \mathrm{S} \text {;"” }\end{array}$ \\
\hline $\mathbf{3}$ & $\mathrm{o}-$ & $\begin{array}{l}\text { "o determinante de um nome (Dn) é idêntico ao sujeito (S) } \\
\text { (que não é o falante nem o ouvinte): Dn = S." }\end{array}$ \\
\hline $\mathbf{4}$ & $\begin{array}{l}\mathrm{t}-\infty \mathrm{m}-\infty \varnothing-\infty \\
(\mathrm{V}>\varnothing)\end{array}$ & "o determinante é ser humano indefinido: D = H." \\
\hline
\end{tabular}

De acordo com Cabral (2001, p. 237), a existência de temas que não ocorrem com esses prefixos levou Rodrigues a distinguir dois tipos de temas em Tupinambá: os que se combinam com os prefixos relacionais e os que não se combinam com esses prefixos. Propôs também uma subdivisão dos temas que se combinam com os prefixos relacionais em duas classes: Classe I e Classe II. Tomou como base para essa subdivisão a ocorrência dos alomorfes do prefixo $\mathrm{R}^{1}$ : com o alomorfe $\varnothing$ - deste prefixo combinam-se temas da Classe I, com o alomorfe $r$-, os da Classe II. Além disso, propôs que a distribuição dos alomorfes dos prefixos 2 e 4 com temas das Classes I e II constituem as bases para a divisão dessas classes morfológicas de temas em subclasses:

Quadro 2: Divisão dos temas proposta por Rodrigues (1981) (quadro extraído de Cabral 2001: 237)

\begin{tabular}{|c|c|c|c|c|c|}
\hline & Subclasses & 1 & 2 & 4 & Exemplos \\
\hline \multirow{2}{*}{$\begin{array}{l}\text { Temas } \\
\text { da } \\
\text { Classe I }\end{array}$} & Ia & $\varnothing-$ & i- & $\varnothing-$ & $\begin{array}{l}\text { akáy 'cabeça', áß ‘cabelo’, kó } \\
\text { 'roça', sý 'mãe', taté 'desviando-se } \\
\text { de’, sém 'sair', kér 'dormir' }\end{array}$ \\
\hline & $\mathrm{Ib}$ & $\varnothing-$ & i- & m- & $\begin{array}{l}\text { pó ‘mão’, pír 'pele’, posáy } \\
\text { 'remédio', poraséy 'dançar', pytá } \\
\text { 'ficar' }\end{array}$ \\
\hline \multirow{4}{*}{$\begin{array}{l}\text { Temas } \\
\text { da } \\
\text { Classe } \\
\text { II }\end{array}$} & IIa & $\mathrm{r}-$ & S- & t- & $\begin{array}{l}\text { esá ‘olho', oßá 'rosto', asém } \\
\text { 'gritar', enoné 'diante de', ekó ‘estar } \\
\text { em movimento', e’õ 'morrer' }\end{array}$ \\
\hline & IIb & $\mathrm{r}-$ & $\mathrm{t}-$ & t- & $\begin{array}{l}\text { úß 'pai', a’ýr 'filho (em rel. ao pai)', } \\
\text { yßýr 'irmão mais moço', úr 'vir', úß } \\
\text { 'estar deitado', ár 'tomar' }\end{array}$ \\
\hline & IIc & $\mathrm{r}-$ & S- & $\varnothing-$ & ók 'casa', u'ú $\beta$ 'flecha' \\
\hline & IId & $\mathrm{r}-$ & S- & $(\mathrm{V}>\varnothing-)$ & $\begin{array}{l}\text { apé ‘caminho', ekúj 'cuia', epanak } \\
\text { 'cesto', epotí 'defecar', epynõ } \\
\text { 'emitir gases' }\end{array}$ \\
\hline
\end{tabular}




\begin{tabular}{|c|c|c|c|c|l|}
\hline $\begin{array}{c}\text { Temas } \\
\text { da } \\
\text { Classe } \\
\text { III' }\end{array}$ & III & --- & -- & --- & $\begin{array}{l}\text { arár 'arara', ajurú 'papagaio', tapi'ír } \\
\text { 'anta', arasá 'araçá', yßák 'céu', } \\
\text { kwár 'sol' }\end{array}$ \\
\hline
\end{tabular}

Rodrigues (1996), ao esclarecer a função dos prefixos relacionais, destaca que esses morfemas servem tanto para marcar a contiguidade sintática de um determinante com respeito ao elemento por ele determinado quanto as relações de dependência desenvolvidas entre os dois. Essas relações de dependência existem entre sujeito/verbo intransitivo, objeto/verbo transitivo, objeto/ posposição e genitivo/nome. Cabral (2001, p. 240) ressalta que, em todas essas combinações, o elemento núcleo é obrigatoriamente marcado por prefixos relacionais.

É inegável a existência de prefixos relacionais na família Tupí-Guaraní, e a descrição dos relacionais do Tupinambá proposta por Rodrigues tem servido como referência aos trabalhos descritivos posteriormente realizados acerca das línguas dessa família linguística. Tais trabalhos têm confirmado, conforme assegura Cabral (2001, p. 238), a existência de prefixos cognatos dos relacionais do Tupinambá e do Guaraní Antigo nas línguas documentadas, bem como o importante papel que esses prefixos têm nas gramáticas dessas línguas.

Cabral (2001), tomando como base os estudos de Rodrigues (1981, 1996), amplia a discussão acerca dos prefixos relacionais ao sublinhar alguns aspectos da sua funcionalidade, explicitando os problemas que apresentam análises linguísticas que os tratam como marcas gramaticais dissociadas umas das outras e mostrando a natureza de algumas mudanças ocorridas no sistema de relacionais original do Tupí-Guaraní, durante a trajetória particular de algumas línguas.

Sobre a funcionalidade da flexão relacional encontrada nas línguas TupíGuaraní, Cabral afirma que:

[...] constitui, portanto, uma estratégia para licenciar, na sintaxe, o que no léxico é relativo, ou seja, o que está fadado a ser relacionado a um determinante. Contrariamente aos elementos lexicais relativos, os elementos não-relativos (absolutos) são livres para operarem na sintaxe, porém não como elementos dependentes. Nessas línguas, raízes verbais, posposições e nomes possuíveis são os elementos lexicais relativos, e raízes nominais não-possuíveis e dêiticos são os elementos absolutos.

\footnotetext{
12 À classe III pertencem os temas identificados por Rodrigues (1981) que não recebem flexão relacional. São temas absolutos ou independentes. Isto é, são aqueles cujos referentes têm existência própria. Por outro lado, às classes I e II pertencem os temas dependentes ou relativos, ou seja, são aqueles cujos referentes têm existência relativa, por isso, requerem um determinante. Nessas duas classes, estão incluídos os temas verbais e posposicionais e parte dos temas nominais (os que se referem a partes de um todo: partes do corpo, das plantas, relações de parentesco e bens culturais concebidos como parte dos seus respectivos fazedores e/ou usuários).
} 
Todos esses elementos têm em comum a propriedade de funcionar como argumento e como predicado, o que os distingue dos outros elementos listados no léxico, os quais são de natureza gramatical (partículas e afixos). As estruturas resultantes da flexão relacional têm em comum núcleo flexionado por um prefixo relacional, o qual exige, permite ou exclui a expressão sintática do determinante (Cabral, 2001, p. 240).

Baseando-se, portanto, na funcionalidade dos relacionais, Cabral (2001, p. 241) propõe a seguinte descrição dos prefixos relacionais:

I. [NOM $\mathbf{R}^{1}$-NÚCLEO] - o Relacional 1 requer que o determinante se posicione imediatamente à esquerda do núcleo e forme com este uma unidade sintática.

II. (NOM) [ $\mathbf{R}^{2}$-NÚCLEO] (NOM) - o relacional 2 permite a expressão sintática do determinante, porém fora do sintagma em que o núcleo se encontra.

III. [ $\mathbf{R}^{3}$-NÚCLEO] - o relacional 3 indica que o determinante de um núcleo é correferente com o sujeito da oração principal, o qual pode ou não estar sintaticamente presente no contexto;

IV. [R $\mathbf{R}^{4}$-NÚCLEO] - o relacional 4 especifica que o determinante de um núcleo é genérico e humano e exclui a expressão sintática desse determinante.

Cabral (2001, p. 242) mostra que, embora Rodrigues (1981) tenha estabelecido uma proposta coerente para a análise da flexão relacional, alguns autores optaram em realizar uma interpretação dos prefixos relacionais 1, 2, 3 e 4 como funcionalmente dissociados uns dos outros: Jensen ${ }^{13}$ (1990, 1997) e Payne (1994) consideraram o prefixo relacional 1 como linker e o prefixo relacional 2 como marca de terceira pessoa; Dobson (1988), seguindo possivelmente Nicholson (1977), considerou o $\mathrm{R}^{1}$ como marca de objeto e o $\mathrm{R}^{2}$ ora é analisado como marca de posse, ora como terceira pessoa sujeito, ora como terceira pessoa objeto; Kakumasu (1986, p. 336), conforme observado por Corrêa da Silva (1997, p. 29) considerou os prefixos relacionais do Ka'apór tanto como prefixos pessoais usados com verbos transitivos, quanto como pronomes possessivos. Em se tratando do $\mathrm{R}^{4}$, Cabral afirma que poucos são os linguistas que o têm considerado como um morfema.

A fim de fortalecer a proposta de análise dos prefixos relacionais como propôs Rodrigues (1981), Cabral (2001, p. 242-244) tece uma série de argumentos que fragiliza interpretações alternativas:

- interpretações dos prefixos relacionais como marcas dissociadas uma das outras não se sustentam, pois os relacionais são mutuamente exclusivos, o que constitui uma das bases para a análise desses prefixos como membros de um mesmo paradigma flexional;

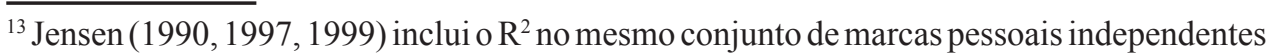
que ela reconstrói para o PTG: če (r) ‘1sg'; oré (r) ‘1 excl.'; jané (r) ‘1 incl.'; né (r) ‘2sg'; pé (r) '2pl'; i- ts $\sim$ t- '3' (Jensen, 1999:147 apud Cabral, 2001, p. 242). 
- a análise do $\mathrm{R}^{2}$ como uma marca pessoal integrando um paradigma de pronomes independentes é problemática, pois viola princípios de análise linguística e nega o comportamento de mútua exclusividade dos prefixos; e

- embora os prefixos relacionais não sejam de natureza pronominal, eles indicam o determinante de um núcleo, especificando, entre outras coisas, a contiguidade sintática do primeiro em relação ao segundo, a correferencialidade do determinante com o sujeito da oração, e o traço humano-genérico do determinante. Por fazerem indicações desse tipo, os relacionais são muitas vezes, equivocadamente, interpretados como marcas pessoais.

\section{Uma descrição dos relacionais em Kaiowá}

John Taylor e Audrey Taylor (1966) consideraram o $R^{2}$ como marca de terceira pessoa na relação genitivo/nome, isso quando o $R^{2}$ é $i$ - ou $h$-; quando o $\mathrm{R}^{2}$ é $t$ - os autores os consideraram como parte da raiz do nome. Também consideraram o $\mathrm{R}^{4}$ ora como parte da raiz do nome, ora como terceira pessoa não-possessiva. $\mathrm{O} R^{3}$ é analisado como marca de terceira pessoa nos nomes cujo sujeito a quem se refere está presente na sentença. Nos predicados verbais, o $R^{2}$ $h$ - é analisado como parte da raiz do verbo, sendo substituído pelo $R^{l} r$ - quando o seu objeto de primeira ou segunda pessoa o precede. Nos verbos em que o $R^{2}$ é $i$-, J. Taylor \& A. Taylor (1966) o consideraram como um "Formador de Raiz Transitiva", sendo sua ausência obrigatória se o objeto de primeira ou segunda pessoa precede o verbo ${ }^{14}$. Em sua "Gramática Pedagógica da Língua Kaiuá" $(\mathrm{s} / \mathrm{d})$, o casal de missionários mantém a noção de que - $i$ e $o$ - são marcas de terceira pessoa ( $R^{2} \mathrm{e} R^{3}$, respectivamente). Nos verbos transitivos que recebem o $R^{2} i$-, embora indiquem que se trata de um "prefixo de objeto", nas segmentações ele vem acoplado ao prefixo pessoal de sujeito (ai- erei-, oi-, jai- oroi-, pei-), e o $R^{2} h$ - é compreendido como parte da raiz do verbo. Não há nenhuma menção acerca do que consideramos como $R^{4}$.

Bridgeman (2001) analisou o $R^{2}(i-, h-)$ como marca de terceira pessoa na relação genitivo/nome e $R^{3}$ como terceira pessoa quando o seu referente é mesmo do sujeito. Sobre o $R^{1}$ e o $R^{4}$ não propões nenhuma análise. Ao tratar da regência verbal, considera o alomorfe $h$ - do prefixo $R^{2}$ como parte inicial do verbo, o qual é substituído por $r-\left(R^{I}\right)$ ao ser precedido pelas marcas de primeira ou segunda pessoa na função de objeto do verbo, enquanto que o alomorfe $-i$ do prefixo $\mathrm{R}^{2}$ nos verbos é considerado como um elemento combinado com o prefixo pessoal na função de sujeito.

Cardoso (2008) reconhece a existência de prefixos relacionais na relação possuidor/possuído, o que, em parte, aproxima sua análise da proposta de Rodrigues. No entanto, não considera a função dos relacionais de marcar

\footnotetext{
${ }^{14}$ J. Taylor \& A. Taylor (1966, p. 51) observa que o $i$ - possui formas variadas: -j- precedendo
} raiz de vogal oral inicial, -nh- precedendo raiz de vogal nasal inicial, zero precedendo glotal. 
contiguidade e não-contiguidade dos determinantes. Essa autora assume que sua análise se fundamenta em Seki (2000) e em Velazquez-Cartillo (1996) e, seguindo Seki (2000), afirma que os relacionais serviriam para indicar (a) se a referência do possuidor é específica ou indefinida, considerando sua função na construção; (b) o tipo de referência expressa; e (c) o tipo de construção. Para ela, portanto,

[...] entre os nomes possuídos, os prefixos relacionais exercem a função especificação do possuidor, por intermédio dos prefixos relacionais $\{\mathrm{r}-\sim$ $\varnothing-\}$ e $\{\mathrm{i}-\sim \mathrm{h}-\}$, em que se pode especificar o tipo de pessoa que preenche o argumento nominal (possuidor) e a função - indefinitude do possuidor, por meio do prefixo relacional $\{\mathrm{t}-\}$, em que não se pode especificar a pessoa do possuidor que, então, fica indefinido (Cardoso, 2008, p. 37).

Considerando a afirmação de Velazquez-Castillo (1996, p. 10) para o Guaraní Paraguaio, Cardoso assume que, em Kaiowá, a alternância entre $r$ - $\left(R^{I}\right)$ e $h$ - $\left(R^{2}\right)$, em estruturas genitivas é determinada segundo o fato de o possuidor ser ou não uma terceira pessoa. Ou seja, se o possuidor for uma primeira ou segunda pessoa, $r$ - ocorre, enquanto que $h$-ocorre se o possuidor é uma terceira pessoa. Os exemplos dados por Velazquez-Castillo e reproduzidos por Cardoso (2008, p. 37) são: che-rera 'my name', hera 'his/her name'. Cardoso acrescenta, ainda, para indicar a alternância dos prefixos relacionais em Kaiowá os seguintes exemplos: tape ( $t$ - possuidor indefinido = caminho de alguém), rape ( $r$-com possuidor de $1^{\mathrm{a}}$ e $2^{\mathrm{a}}$ pessoa $=$ meu ou teu caminho) e hape ( $h$-com possuidor de $3^{\text {a }}$ pessoa = seu caminho / caminho (dele)). Contudo, sem levar em consideração a ideia expressa por Rodrigues (1981) de contiguidade ou nãocontiguidade do determinante, exclui a ocorrencia de sintagmas Maria r-ape 'caminho da Maria', em que o possuidor é uma terceira pessoa expressa por um nome. E nessa construção Logo, $r-\left(R^{l}\right)$ relaciona uma terceira pessoa ao tema possuído. No exemplo em pauta, o determinante está contíguo, precedendo imediatamente o determinado, formando com este um sintagma; é isso que faz $r$ - ocorrer em xe r-ape 'meu caminho', nde r-ape 'teu caminho', ore r-ape 'nosso (excl.) caminho', nhande r-ape 'nosso (incl.) caminho', pende r-ape 'caminho de vocês' e Maria r-ape 'caminho de Maria', ou seja, a combinação de um tema relativo com $\mathrm{r}$ - deve-se à contiguidade do possuidor, seja ele expresso por forma pronominal ou por um nome.

Diante disso, considerar que os prefixos relacionais que se afixam aos nomes possuídos exercem unicamente a função de especificação do possuidor, por intermédio dos prefixos relacionais $r-\sim \varnothing$ - e $i$ - $\sim h$-, como propôs Cardoso, é desconsiderar o papel morfossintático que eles exercem para marcar relações de dependência (subordinação e determinação) e de contiguidade sintática entre um tema determinado e o seu determinante (contíguo e não contíguo).

Cardoso (2008, p. 38) identificou o $R^{3} o$-, mas o analisou como um reflexivo que codifica apenas um possuidor de terceira pessoa. $\mathrm{O} R^{4} t$ - foi descrito por ela 
como um relacional indefinido. Concluiu, portanto, que $o$ - é um possuidor de $3^{\text {a }}$ pessoa co-referente; e que $r$ - ou $\varnothing$ - indica que o possuidor expresso no sintagma nominal genitivo é a $1^{\mathrm{a}}$ ou a $2^{\mathrm{a}}$ pessoa; e que $h-\sim i$ - $\sim t$ - indicam o possuidor de $3^{\text {a }}$ pessoa deslocado da posição original. Ora, esta definição embora seja calcada na definição de Rodrigues, difere desta por Rodrigues tratar $h-\sim i$ - $\sim t$ - como alomorfes do prefixo relacional $\mathrm{R}^{3}$ - e não como expressões de uma terceira pessoa.

Embora identifique alomorfia nos relacionais, Cardoso (2008) não propôs uma divisão dos temas em classes e subclasses, como tradicionalmente tem sido feito por estudiosos de línguas Tupí-Guaraní que seguem o modelo de análise proposto por Rodrigues (1981). Cardoso (2008, p. 77), em sua proposta de classificação dos verbos em transitivos, intransitivos ativos, intransitivos inativos e cópula, assumiu uma análise alternativa para os relacionais. Afirmou que os verbos intransitivos ativos não são codificados com prefixos relacionais, mas os verbos intransitivos inativos sim. No caso dos verbos transitivos, Cardoso sugeriu que os prefixos relacionais ocorreriam para indicar propriedades próprias da categoria de voz, tomando como base a proposta apresentada por Payne (1994). Nesse sentido, chamou de voz direta as construções em que verbos transitivos recebem os prefixos $i-\sim h-\sim \varnothing$-, e de voz inversa as construções em que verbos transitivos recebem o prefixo $r$ - Em seu entendimento, a mudança de uma construção direta para uma construção inversa é completamente gramaticalizada em termos da Hierarquia de Pessoa $(1>2>3)$, e quando estão envolvidas duas terceiras pessoas, a construção é gramaticalizada como direta ${ }^{15}$ :

O Kaiowá codifica o argumento externo (A), junto a verbos transitivos de sentenças independentes, por meio dos prefixos da série $\mathrm{I}^{16}$, seguido do morfema $\{\mathrm{i}-\}$, quando (A) é hierarquicamente mais alto que o argumento interno $(\mathrm{O})$, e codifica o argumento interno nestas sentenças, por meio dos clíticos pronominais da série $\mathrm{II}^{17}$, seguido do marcador de voz inversa \{r\}. Assim sendo, as construções marcadas com a série II/r- são tidas como construções inversas, tendo o morfema $\{r-\}$ como marcador de inverso, e quando as construções são marcadas com a série I/i-, são tidas como construções diretas, tendo o morfema $\{\mathrm{i}-\}$ como marcador de voz direta (Cardoso, 2008, p. 77).

\footnotetext{
${ }^{15}$ Em sua descrição, Cardoso (2008, p. 78) informa que o prefixo relacional $\{\mathrm{i}-\}$ apresenta variação alofônica $[i-\sim \tilde{l}-\sim \tilde{1} \mathrm{n}-\sim i n-\mathrm{e} \emptyset$ - $]$ e alomórfica $\{\mathrm{i}-\sim \mathrm{h}-\sim \mathrm{t}-\}$, sendo que este último alomorfe ocorre apenas com núcleos nominais possuídos, provavelmente quando o núcleo é um nome que indica relação de parentesco.

${ }^{16}$ A autora considera como marcadores da série I os prefixos pessoais de sujeito a- ' $1 \mathrm{sg}$.', ere- '2sg.', o- '3', oro- ' 1 exclusiva', ja- ' 1 inclusiva', pe- ' $2 \mathrm{pl}$ '.

${ }^{17}$ A autora considera como clíticos pronominais xe ' 1 ', nde ' 2 ', ore ' 1 .excl', nhande ' 1 .incl', pende '2pl' Em nossa proposta de análise, consideramos como pronomes independentes, uma vez que não demonstram ter propriedades de clíticos.
} 
Reproduzimos, a seguir, dois dos exemplos dados por Cardoso ${ }^{18}$ :

(3) [defere'Ja a've]

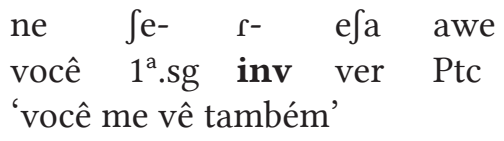

(4) [Se ahai'hu ma'riape]

Se a- h- anhu maria -pe

você $1^{\text {a }}$.sg dir amar maria Acus

'eu amo Maria'

Em que pese a possibilidade de se considerar os relacionais como formadores de vozes, tomando como critério de análise a hierarquia de pessoa, essa proposta não dá conta de revelar a função fundamental da existência dos prefixos relacionais nas línguas Tupí-Guaraní, uma vez que a função morfossintática para estabelecer relações de dependência entre sujeito/verbo intransitivo e objeto/verbo transitivo, bem como a de marcar a contiguidade e não-contiguidade sintática de argumentos, em geral, não é contemplada nesse modelo de análise. Além disso, perde-se a possibilidade de visualizar e compreender os padrões de alinhamento que a língua Kaiowá possui, uma vez que é por meio da noção de contiguidade e não contiguidade sintática, marcadas pelos relacionais 1 e 2, que os padrões de alinhamento nominativo/ absolutivo; absolutivo; nominativo/acusativo e absolutivo/ergativo se revelam, assim como foi demonstrado por Grannier (1997) para o Guaraní Antigo, assim como o padrão nominativo (Cabral, 2001) o padrão nominativo também ativo nas língua Tupí-Guaraní. Considerar também a existência de voz direta e voz inversa é divergir do que tem sido compreendido nos estudos de línguas TupíGuaraní, como proposto por Rodrigues (1947), que descreve sete vozes para o Tupinambá, sendo essas mesmas encontradas em outras línguas da mesma família. As vozes são as seguintes: ativa, em que o sujeito é simplesmente agente da ação indicada pelo verbo; causativa, em que o sujeito faz outrem praticar a ação, em vez de ele mesmo praticá-la; causativo-prepositiva, formada sobre os verbos transitivos, na qual o sujeito faz com que alguém pratique a ação sobre outrem; causativo-comitativa, em que o sujeito faz outrem exercer a ação, praticando-a ele também; portanto, o sujeito e o complemento praticam a ação conjuntamente, em companhia, sendo ambos agentes imediatos; e voz média, em que o sujeito é especialmente interessado na ação. Conforme Rodrigues

\footnotetext{
${ }^{18}$ São os exemplos 84 a e 84 b da tese de Cardoso (2008, p. 78). Neles, mantivemos a forma como a pesquisadora apresentou os dados na sua tese: uma transcrição fonética, uma transcrição fonológica, baseando-se em seu estudo fonológico da língua Kaiowá (Cardoso, 2007). Também mantivemos a segmentação e a descrição dos morfemas propostas por ela.
} 
(1947, p. 20), no Tupinambá temos três modalidades de média: média reflexiva, média recíproca e média propriamente dita. A voz média reflexiva é aquela em que o sujeito pratica a ação sobre si mesmo, sendo, simultaneamente, agente e paciente; na voz média recíproca os sujeitos (plural) praticam a ação uns sobre os outros, mutuamente; e na voz média propriamente dita, o sujeito pratica a ação para si, em seu benefício.

Como explicar que uma voz é ao mesmo tempo causativa e inversa, por exempolo? Diante disso, considerar a existência das vozes direta e inversa marcada pelos prefixos relacionais $R^{l}$ - e $R^{2}$ - é admitir que tais morfemas não sejam relacionais e sim marcadores de vozes, e que as línguas Tupí-Guaraní apresentariam a coocorrência de vozes disitntas em uma mesma predicação: ativa-direta, ativa-inversa, causativo-direta, causativo-inversa, causativocomitativo-direta e causativo-comitativo-inversa, por exemplo. Cabe destacar ainda que Voz, em línguas Tupí-Guaraní, são expressas por meio de derivação. Os morfemas de voz são todos derivacionais; já os prefixos relacionais constituem um paradigma flexional.

Sobre a estrutura objeto/posposição, nenhum dos trabalhos sobre a língua Kaiowá, até o momento, destacou a funcionalidade dos relacionais. Fundamentados em Rodrigues (1981) e Cabral (2001), apresentamos nas seções seguintes deste artigo a nossa proposta de análise para os prefixos relacionais da língua Kaiowá, que ocorrem nas seguintes estruturas: genitivo/nome, objeto/ verbo transitivo, objeto/posposição e sujeito/verbo descritivo.

\section{Descrição dos prefixos relacionais e classes de temas em Kaiowá}

Inicialmente, apresentamos a divisão dos temas Kaiowá em classes, conforme Rodrigues (1981). Para os temas que se combinam com prefixos relacionais, assumimos que estes estão distribuídos nas Classes I e II, levando em consideração a ocorrência dos alomorfes do prefixo relacional $\mathrm{R}^{1}$. À Classe III pertencem os temas que não se combinam com prefixos relacionais. Consideramos ainda a subdivisão das Classes I e II em subclasses, tomando como critério a combinação dos temas relativos com os alomorfes dos prefixos relacionais 2 e 4 . Os dados utilizados aqui provêm de diversas fontes: Taylor \& Taylor (1966, s/d), Barros (2014), além de dados de primeira mão, coletados em campo (Martins, 2015, arquivo pessoal). ${ }^{19}$

\subsection{Classes de temas}

Em Kaiowá, como nas demais línguas Tupí-Guaraní, existem duas classes de temas: a dos relativos ou dependentes e a dos absolutos ou independentes.

\footnotetext{
${ }^{19}$ Os dados de primeira mão utilizados neste artigo foram coletados na Reserva Indígena de Dourados e na Terra Indígena Panambizinho, que também está localizada no município de Dourados-MS.
} 
Do primeiro tipo, fazem parte os temas cujos referentes têm existência relativa, portanto, requerem um determinante; do segundo tipo fazem parte os temas cujos referentes têm existência própria e, por isso, não necessitam de determinantes.

Temas relativos em Kaiowá são temas verbais, posposicionais e nominais. Destes últimos, são relativos os que se referem a partes do corpo e das plantas, a sensações e qualidades, e a relações de parentesco e artefatos compreendidos como parte dos seus respectivos fazedores, donos ou usuários. Esses temas relativos constituem as Classes I e II. Os que pertencem aà classe 1 se combinam com o alomorfe Ø- do relacional $R^{I}$-; já os temas da classe 2 se combinam com o alomorfe $r$ - do mesmo morfema relacional.Temas absolutos, por sua vez, são aqueles que têm como referente elementos da natureza, animais e plantas: $y$ 'água', yvy 'terra', jasy 'lua', ita 'pedra', jagwa 'cachorro', jagwarete 'onça', mbarakaja 'gato', mbói 'cobra', avati 'milho', pakova 'banana', mandi'o 'mandioca', etc. Conforme Rodrigues (1981), os temas absolutos formam a Classe III.

\section{Classe I}

Como afirmamos, à classe I pertencem os temas relativos, cuja indicação de contiguidade sintática do determinante é marcada pelo alomorfe Ø- do prefixo relacional 1:

(5) xe $\varnothing-$ po

$1 \quad \mathbf{R}^{1}-$ mão

'minha mão'

(6) nde Ø- sy

$2 \quad \mathbf{R}^{1}-\quad$ mãe

'tua mãe'

(7) Fábio Ø- kyha

Fábio $\mathbf{R}^{1}$ - rede

'rede do Fábio'

(8) Amambai Ø- py

Amambai $\quad \mathbf{R}^{1-}$ dat

'para Amambai'

Os temas da Classe I marcam a não-contiguidade sintática do determinante por meio do alomorfe $-i$ do prefixo relacional 2:

(9) $\mathbf{i}^{-}$po

$\mathbf{R}^{2}$ - mão

'mão dele/dela' 
(10) i- $^{-}$sy

$\mathbf{R}^{2}-$ mãe

'mãe dele/dela'

(11) i- kyha

$\mathbf{R}^{2}$ - rede

'rede dele/dela'

O alomorfe $-i$ do prefixo relacional $R^{2}$ - ocorre em temas iniciados por consoante, exemplos (9), (10) e (11); o alomorfe $i j$ - se combina com temas orais iniciados por vogal, exemplos (12), (13) e (14); o alomorfe inh- se combina com temas nasais iniciados por vogal, exemplos (15), (16) e (17); e o alomorfe $h i$ - ocorre em temas iniciados por oclusiva glotal, exemplos (18), (19) e (20).

(12) $\mathbf{i j -}$ apysa

$\mathbf{R}^{2}$ - ouvido

'ouvido dele/dela'

(13) ij- igwéi

$\mathbf{R}^{2}$ - ter.sede

'sede dele/dela'

(14) $\mathbf{i j}^{-} \quad$ aju

$\mathbf{R}^{2}$ - pescoço

'pescoço dele/dela'

(15) inh- apekũ

$\mathbf{R}^{2}$ - língua

'língua dele/dela'

(16) inh irũ

$\mathbf{R}^{2}-\quad$ companheiro

'companheiro dele/dela'

(17) inh- akã

$\mathbf{R}^{2}-\quad$ cabeça

'cabeça dele/dela'

(18) hi- 'ávy

$\mathbf{R}^{2}$ - cabelo

'cabelo dele/dela' 
(19) hi- 'ã $\quad$-gwe

$\mathbf{R}^{2}$ - alma -RETR

'alma dele/dela'

(20) hi- 'ári

$\mathbf{R}^{2}-\quad$ SOBRE

'em cima dele/dela'

Os temas dessa classe iniciados por consoante recebem o alomorfe $o$ - do relacional 3, quando o determinante é correferente com o sujeito da oração principal, podendo este estar ou não sintaticamente expresso:

(21) Sara o- japo o- kyha

Sara 3- fazer $\mathbf{R}^{3}$ - rede

'Sara fez sua própria rede'

(22) ha'e o- juka o- memby

esta 3- matar $\mathbf{R}^{3}-\quad$ filho/a (na fala da mulher)

'esta matou o próprio filho'

(23) Fábio o- h- exa o- sy

este 3- $R^{2}$ ver $\mathbf{R}^{3}-$ mãe

'Fábio viu a própria mãe'

O alomorfe ho- desse mesmo prefixo, se combina com temas iniciados por oclusiva glotal:

(24) Maria o- mombu ho- 'ávy

Maria 3- arrancar $\mathbf{R}^{3}$ - cabelo

'Maria arrancou o próprio cabelo'

(25) Sara ogw- er- u ho- 'ója (empr.)

Sara 3- CC- vir $\mathbf{R}^{3}$ - panela

'Sara trouxe sua própria panela'

Rodrigues (1981) estabelece para o Tupinambá uma subdivisão da Classe I em duas subclasses: Ia e Ib. O critério utilizado é a distribuição alomórfica do prefixo relacional 4 , cuja função é indicar que o determinante do núcleo é genérico e humano. Este prefixo exclui a expressão sintática desse determinante. Em Tupinambá havia dois alomorfes para essa função nos temas da Classe I: 
$\varnothing$ - (Subclasse Ia) e $m$ - (Subclasse Ib), este último alomorfe ocorria em temas relativos iniciados $\operatorname{com} p$. Kaiowá retém apenas alguns temas nessa classe, como veremos adiante. Entretanto, vários outros temas dessa subclasse passaram a integrar a classe 1a, como é o caso do tema 'mão' do exemplo seguinte.

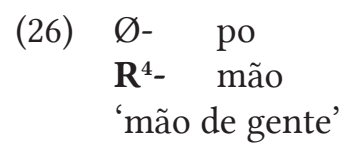

Alguns dos temas que permaneceram nessa subclasse temática são porahéil mborahéi 'canto' e 'pohã/mohã 'remédio', sendo que a forma mohã passou a significar tanto "remédio, medicina" como "feitiço'. Tais formas são utilizadas na variedade da língua Kaiowá falada na aldeia Panambizinho, Dourados-MS e foram registradas por Concianza et al (2015), mas são também usadas em outras variedades dialetais do Kaiowá.

\section{Classe II}

À Classe II pertencem os temas que marcam a contiguidade sintática dos determinantes por meio do alomorfe $r$-do prefixo relacional $l$ :

(30) xe r- u

$1 \quad \mathbf{R}^{1-}$ pai

'meu pai'

(31) nde $\mathbf{r}-$ esa

$2 \quad \mathbf{R}^{1}$ - olho

'teu olho'

(32) Fábio r- óga

Fábio $\mathbf{R}^{1}-$ casa

'casa de Fábio'

(33) ore $\quad \mathbf{r}-$ esarái

1.excl $\mathbf{R}^{1}$ - esquecer

'nosso esquecimento, nós esquecemos'

(34) nhande $\mathbf{r}-$ ehe

1.incl $\quad \mathbf{R}^{1}-\quad$ REL

'em respeito a nós, por nós 
Os alomorfes do prefixo $\mathrm{R}^{2}$ - dos temas da classe II são $h$ - e $t$-. Sendo este último restrito aos nomes que designam relações de parentesco.

Subclasse IIa:

(35) h- esa

$\mathbf{R}^{2}-\quad$ olho

'olho dele/dela'

(36) h- óga / óy

$\mathbf{R}^{2}-\quad$ casa

'casa dele/dela'

(37) h- ova

$\mathbf{R}^{2}$ - rosto

'rosto dele/dela'

Subclasse IIb:

(38) t- úvy / úva

$\mathbf{R}^{2}-\quad$ pai

'pai dele/dela'

(39) t- a'ýry a'ýra

$\mathbf{R}^{2}-\quad$ filho

'filho (em relação ao pai) dele/dela'

(40) t- yvýry

$\mathbf{R}^{2}$ - $\quad$ irmão mais moço

'irmão mais moço dele/dela'

Os temas da Classe II se combinam com o alomorfe $g w$ - do relacional 3. O desenvolvimento histórico desse alomorfe seguiu, muito provavelmente os estágios seguintes: o- $>*_{\text {ow }}>*_{\text {ogw }}>$ gw $/ \ldots$ V. Alguns exemplos da ocorrência de temas da classe II com o alomorfe $g w$ - são:

(41) o- h- exa ha o- mo- $\tilde{i}$ gw- endy ij- apyte -py $3 \mathrm{R}^{2}$ - ver e 3- CAUS estar $\mathbf{R}^{3}$ - saliva $\mathrm{R}^{2}$ meio.da.cabeça -LP 'ele vê e coloca sua saliva no meio da cabeça (do menino)' (Barros 2014: 147)

(42) ha'e ogw- era- ha $\mathrm{gw}^{-}$óga

este 3- CC- ir $\mathbf{R}^{3}-$ casa 
‘ele levou sua própria casa’ (Barros 2014: 151)

(43) he'i gw- embireko $\varnothing$ - pe a- ha ta a- nhemitỹ 3.dizer $\mathbf{R}^{3}$ - esposa $\mathrm{R}^{1}-\mathrm{DAT}$ 1- $^{-}$ir EXO 1- plantar 'ele disse a própria esposa: vou plantar' (Barros 2014: 151)

Os temas da classe II se combinam com os alomorfes $t$ - e $\varnothing$ - do relacional 4. Rodrigues observou que, em Tupinambá, alguns temas podiam perder a vogal inicial quando em sua forma genérica e humana (apé 'caminho'> pé 'caminho de gente'; ekúj 'cuia' > kúj 'cuia de gente'; epanak 'cesto'> panak 'cesto de gente', epoti 'defecar'> poti 'defecar de gente'; epynõ 'emitir gases' > 'emitir gases de gente’). Em Kaiowá não há perda de vogal inicial na forma genérica e humana.

Levando em consideração a divisão de classes e subclasse de temas proposta por Rodrigues (1981), e com base nos dados disponíveis da língua Kaiowá, verificamos que os temas da classe II se subdividem em três subclasses: IIa, IIb e IIc. Pertencem à subclasse IIa os temas que se combinam com o alomorfe $r$ do prefixo $R^{1}$-, com o alomorfe $h$ - do prefixo $R^{2}$, com o alomorfe $g w$-do prefixo $R^{3}$ e com o alomorfe $t$ - do prefixo $R^{4}$; à subclasse IIb pertencem os temas que se combinam com o alomorfe $t$ - do prefixo $R^{2}$ e à subclasse IIc pertencem os temas que se combinam com o alomorfe $\varnothing$ - do prefixo $R^{4}$. Em Kaiowá a maioria dos antigos temas que pertenciamnão à classe IId constituem hoje a Classe IIc, como -ape 'caminho'. Apresentamos, em seguida, o quadro de relacionais do Kaiowá.

\section{Quadro 3: Relacionais do Kaiowá}

\begin{tabular}{|c|c|c|c|}
\hline Relacionais & Função & Morfemas & Observações \\
\hline $\mathrm{R}^{1}$ & $\begin{array}{l}\text { Exige que o determinante } \\
\text { se posicione imediatamente } \\
\text { à esquerda do núcleo e } \\
\text { forme com este uma unidade } \\
\text { sintática. }\end{array}$ & $\varnothing-\infty \mathrm{r}-$ & $\begin{array}{l}\text { Ø- com temas da } \\
\text { Classe I } \\
\text { r- com temas da } \\
\text { Classe II }\end{array}$ \\
\hline $\mathrm{R}^{2}$ & $\begin{array}{l}\text { Permite a expressão sintática } \\
\text { do determinante, porém fora } \\
\text { do sintagma. }\end{array}$ & $\begin{array}{c}\mathrm{i}-\sim \mathrm{ij}-\sim \mathrm{hi}- \\
\infty \mathrm{h}-\infty \mathrm{t}-\end{array}$ & $\begin{array}{l}\text { i- (ij- } \sim \text { inh- } \sim \text { hi- }) \\
\text { com temas da Classe I. } \\
\text { h- e t- com temas da } \\
\text { Classe II. }\end{array}$ \\
\hline $\mathrm{R}^{3}$ & $\begin{array}{l}\text { Indica que o determinante de } \\
\text { um núcleo é correferente com } \\
\text { o sujeito da oração principal, } \\
\text { o qual pode ou não estar } \\
\text { sintaticamente presente no } \\
\text { contexto. }\end{array}$ & o- $\sim$ ho- $\sim \mathrm{gW}-$ & $\begin{array}{l}\text { o- (ho-) com temas da } \\
\text { Classe I. } \\
\text { gw- com temas da } \\
\text { Classe II. }\end{array}$ \\
\hline
\end{tabular}




\begin{tabular}{|c|c|c|c|}
\hline $\mathrm{R}^{4}$ & $\begin{array}{l}\text { Especifica que o determinante } \\
\text { de um núcleo é genérico e } \\
\text { humano e exclui a expressão } \\
\text { sintática desse determinante. }\end{array}$ & t $-\infty \varnothing-\infty$ m- & $\begin{array}{l}\text { t- com temas das } \\
\text { subclasses IIa e IIb; } \\
\varnothing \text { - com temas da classe } \\
\text { Ia e com temas da } \\
\text { subclasse IIc; m- com } \\
\text { temas da classe Ib. }\end{array}$ \\
\hline
\end{tabular}

Consoante Cabral (2001: 234), a presença de quatro relacionais em línguas de todos os ramos da família é também indicativa de que os sistemas de relacionais com apenas dois ou três prefixos, presentes em algumas línguas, devem ser resultantes da redução de um sistema original mais complexo, ocorrida durante o desenvolvimento histórico dessas línguas particulares, como são os casos do Guaraní-Nhandéva e do Guarani Paraguaio. Contudo, conforme pode ser visualizado no quadro 3, o Kaiowá preserva a funcionalidade dos quatro prefixos relacionais.

Quadro 4: Distribuição dos Temas do Kaiowá em Classes e Subclasses

\begin{tabular}{|c|c|c|c|c|c|c|}
\hline Classes & $\begin{array}{c}\text { Subclass- } \\
\text { es }\end{array}$ & $\mathbf{R}^{1}$ & $\mathbf{R}^{2}$ & $\mathbf{R}^{3}$ & $\mathbf{R}^{4}$ & Exemplos \\
\hline \multirow[t]{2}{*}{ Classe I } & Ia & $\varnothing-$ & $\begin{array}{l}\text { i- } \sim \mathrm{ij}-\sim \\
\text { inh- } \sim \\
\text { hi- }\end{array}$ & $\begin{array}{l}\text { o- } \\
\text { ho- }\end{array}$ & $\varnothing-$ & $\begin{array}{l}\text { akã ‘cabeça', ’ávy 'cabelo', } \\
\text { kokwe 'roça', sy 'mãe’, } \\
\text { po ‘mão', pire 'pele', hu’y } \\
\text { 'flecha'. }\end{array}$ \\
\hline & Ib & $\varnothing-$ & i- & o- & $\begin{array}{l}\mathrm{m}-\sim \\
\mathrm{mb}-\end{array}$ & $\begin{array}{l}\text { pohã 'remédio' e porahéi } \\
\text { 'cantar'. }\end{array}$ \\
\hline \multirow{3}{*}{$\begin{array}{c}\text { Classe } \\
\text { II }\end{array}$} & IIa & $\mathrm{r}-$ & h- & gw- & t- & $\begin{array}{l}\text { esa 'olho', ová 'rosto', apé } \\
\text { 'caminho', eko ‘estar em } \\
\text { movimento'. }\end{array}$ \\
\hline & IIb & $\mathrm{r}-$ & $\mathrm{t}-$ & gw- & t- & $\begin{array}{l}\text { úvy, u 'pai', a'y 'filho (em } \\
\text { rel. ao pai)', ajy 'filha' (em } \\
\text { relação ao pai), yvýry 'irmão } \\
\text { mais moço', enonde 'diante } \\
\text { de', amói'io 'avô' }\end{array}$ \\
\hline & IIc & $\mathrm{r}-$ & h- & gw- & $\varnothing-$ & óga 'casa'. \\
\hline
\end{tabular}

De acordo com Cabral (2001: 234), várias mudanças de natureza fonológica ou gramatical ocorridas nas línguas da família teriam resultado na passagem de temas de uma classe ou de uma subclasse a outra, bem como na eliminação de algumas subclasses e/ou no surgimento de novas subclasses:

${ }^{20} \mathrm{O}$ relacional 4, combinando-se com o tema amói 'avô', tem sido realizado ora como t- ora como nh-. 
No Jo'é, por exemplo, com a desnasalização histórica das consoantes nasais em temas com acento oral (Cabral, 2000), a forma absoluta de temas da Classe Ib passou a ser obtida com a sonorização de /p/ (byter-a 'parte do meio' $<\mathrm{R}^{4}$-meio-ARG), isso nos casos em que não houve mudança de classe. O Ka'apor, como observado por Corrêa da Silva (1997:30), teve o seu sistema de relacionais extremamente reduzido com a perda do prefixo relacional 3, e de vários alomorfes dos prefixos 2 e 4 e com a consequente redução do número de subclasses da Classe II. Há vários casos de mudanças de classe de temas em diferentes línguas, como, por exemplo, em Jo'é, em que o alomorfe do prefixo 2 que ocorria em temas da Classe IIa foi reanalisado como parte de alguns temas que receberam uma vogal adicional e passaram para a subclasse IIe (h-ãj > -ahãj 'dente'). No Jo’é e no Emérillon, com o enfraquecimento de *ts para h ou $\varnothing$, o alomorfe do prefixo 2 que ocorria em temas da Classe II se preservou enquanto h- quase só em temas monossilábicos. No Ka'apor, no Jo'é e no Emérillon, vários temas da classe I passaram a constituir uma subclasse distinta com alomorfes Ø- para os prefixos 1, 2 e 3 (Cabral, 2001, p. 234).

Em Kaiowá, algumas mudanças e variações também foram identificadas:

(i) fusão das subclasse Ia e Ib;

(ii) eliminação, na maioria das vairedades Kaiowá da subclasse IId;

(iii) mudança de classe do tema $h u$ ' $i$ 'flecha' (de IIc para I) e de enonde 'diante.de' (de IIa para IIb);

(iv) variação de classe do tema úvy úva 'pai'. (i-túva 'pai dele', Classe I e $t$-úvy 'pai dele', Subclasse IIb). Os mais jovens têm preferido $i$-túva, o que demonstra uma mudança em curso, o que se verifica também com a alternância de outros temas de parentesco: t-ajýry i-tajýra 'filha dele', t-a'ýry $\sim i$-ta'ýra 'filho dele'.

\subsection{Genitivo/Nome em Kaiowá}

Como vimos, os prefixos relacionais marcam a relação de dependência sintática entre determinante e determinado, além de indicar contiguidade e não contiguidade sintática do determinante em relação ao núcleo que determina.

Nas estruturas possessivas, o relacional 1 indica que o determinante precede imediatamente o núcleo, constituindo com ele um único sintagma. Destacamos que a função de possuidor é exercida por um pronome independente ${ }^{21}$ de

${ }^{21}$ Os pronomes independentes são: $x e$ 'primeira pessoa do singular'; nde $\sim$ ne 'segunda pessoa do singular; ore 'primeira pessoa do plural exclusiva'; nhande $\sim$ nhane 'primeira pessoa do plural inclusiva'; peẽ e pende 'segunda pessoa do plural'. Aquele, no entanto, 
primeira ou segunda pessoa ou uma expressão nominal. Seguem exemplos com sy 'mãe', Classe I; esa 'olho', Subclasse IIa; ãi 'dente', Subclasse IIb; e óga 'casa', Subclasse IIc:
(49) xe $\varnothing-$ sy
$1 \quad \mathbf{R}^{1}-\quad$ mãe
'minha mãe'
(50) nde $\varnothing$ - sy
$2 \quad \mathbf{R}^{1}$ - mãe
'tua mãe'

(51) ore $\varnothing-$ sy

1.excl $\mathbf{R}^{1}{ }^{-} \quad$ mãe

'nossa mãe'

(52) nhande $\varnothing$ - sy

1.incl $\mathbf{R}^{\mathbf{1}-}$ mãe

'nossa mãe'

(53) Fábio Ø- sy

1.incl $\mathbf{R}^{\mathbf{1}-}$ mãe

'mãe do Fábio'

(54) xe r- esa

$1 \quad \mathbf{R}^{1}$ - olho

'meu olho'

(55) nde $\mathbf{r}-\quad$ esa

$2 \quad \mathbf{R}^{1}$ - olho

'teu olho'

(56) ore $\mathbf{r}-$ esa

1.excl. $\mathbf{R}^{1}-\quad$ olho

'nosso olho'

(57) nhande $\mathbf{r}-$ esa

1.incl $\mathbf{R}^{1}-$ olho

'nosso olho'

ocorre apenas como sujeito enfático, enquanto este ocorre como possuidor, como objeto de posposição, como objeto de transitivos e como sujeito de verbos descritivos, assim como os demais pronomes desse paradigma. Destaca-se que em Kaiowá, como na maioria das línguas Tupí-Guaraní, não há um pronome independente de terceira pessoa, tão pouco um prefixo possessivo, quer seja de primeira, de segunda ou de terceira pessoa. 
(58) pende r- esa 2pl $\quad \mathbf{R}^{1}$ - olho 'olho de vocês'

(59) xe r- ãi $1 \quad \mathbf{R}^{\mathbf{1}}$ - dente 'meu dente'

(60) nde r- ãi $2 \quad \mathbf{R}^{\mathbf{1}} \mathbf{2}$ dente 'teu dente'

(61) ore r- ãi 1.excl $\mathbf{R}^{\mathbf{1}} \mathbf{-}$ dente 'nosso dente'

(62) nhande r- ãi 1.incl $\mathbf{R}^{\mathbf{1}}$ dente 'nosso dente'

(63) pende r- ãi $2 \mathrm{pl} \quad \mathbf{R}^{\mathbf{1}} \mathbf{-}$ dente 'dente de vocês'

(64) Fábio r- ãi Fábio $\mathbf{R}^{\mathbf{1}} \mathbf{-}$ dente 'dente do Fábio'

(65) xe r- óy $\sim$ óga $1 \quad \mathbf{R}^{\mathbf{1}}$ - casa 'minha casa'

(66) nde r- óy óga $2 \quad \mathbf{R}^{1}$ - casa 'tua casa'

(67) ore r- óy óga 1.excl $\mathbf{R}^{1}$ - casa 'nossa casa'

(68) nhande $\mathbf{r}$ - óy óga 1.incl $\quad \mathbf{R}^{\mathbf{1}}-\quad$ casa 'nossa casa'

(69) pende $\mathbf{r}$ - óy $\sim$ óga 2pl $\quad \mathbf{R}^{\mathbf{1}}$ - casa 'casa de vocês' 
(70) Fábio r- óy óga

Fábio $\mathbf{R}^{\mathbf{1}-}$ casa

'casa de Fábio'

$\mathrm{O}$ relacional $\mathrm{R}^{2}$ - indica que o possuidor não está contíguo ao núcleo possuído, embora muitas vezes ocorra imediatamente precedido ao nome, mas sem formar com este uma unidade sintática. Seguem exemplos com temas da Classe Ia e com temas das Subclasses IIa, IIb e IIc:

Classe Ia:

(71) inh- akã

$\mathbf{R}^{2}-$ cabeça

'cabeça dele/dela'

(72) $\mathbf{i}^{-} \quad$ sy

$\mathbf{R}^{2}$ - mãe

'mãe dele/dela'

(73) ha' $\mathrm{e}^{22}$ i- $\quad$ kokwe

este $\mathbf{R}^{2}-$ roça

'roça dele/dela'

Classe II

Subclasse IIa

(74) h- esa

$\mathbf{R}^{2-}$ olho

'olho dele/dela'

${ }^{22}$ ha'e é um dêitico. Trata-se de um demonstrativo, conforme Rodrigues (1981). Cardoso (2008, p. 104) descreve-o como um pronome de terceira pessoa, mas compreendemos que o mesmo não faz parte do paradigma de pronomes, e sim do sistema de demonstrativos, pois não cumpre a função de possuidor em estruturas genitivas, nem de determinante de verbos transitivos e intransitivos, assim como de complemento de posposições. Pronomes funcionam como determinantes de nomes, como em nde r-oga, mas não ha'e. A construção $h a^{\prime}$ er-oga é agramatical. Isso reforça a identidade dêitica de $h a$ 'e. Cabe ressaltar ainda que, na maioria das línguas Tupí-Guaraní, conforme Cabral (2001: 242-244), os pronomes pessoais existentes são de primeira e segunda pessoa. Há línguas, entretanto, em que demonstrativos passaram a suprir a lacuna de uma terceira pessoa, como em Kayabí, Parintintín e Asuriní do Xingu. Mas nessas línguas os demonstrativos ocorrem como determinantes de nomes, quando os seus respectivos referentes são (+humano). 
(75) h- ova

$\mathbf{R}^{2}$ - rosto

'rosto dele/dela'

(76) h- ape

$\mathbf{R}^{2}$ - caminho

'caminho dele/dela'

Subclasse IIb

(77) t- úvy úva

$\mathbf{R}^{2}-\quad$ pais

'pai dele/dela'

(78) t- a'ýry a'ýra

$\mathbf{R}^{2}$ - filho (em relação ao pai)

'filho dele'

(79) t- yvýry

$\mathbf{R}^{2}$ - $\quad$ irmão.mais.moço

'irmão mais moço dele'

Subclasse IIc

(80) h- óga

$\mathbf{R}^{2}-\quad$ casa

'casa dele'

(81) $\quad \mathbf{h}-\quad$ ója

$\mathbf{R}^{2}$ - panela

'panela dele'

O relacional 3 indica que o possuidor é correferente com o sujeito da oração principal. Em seguida, apresentamos exemplos com temas das Classe I e II:

\section{Classe I:}

(82) o- membyry ndive o- ho ho- 'u kagwĩ

$\mathbf{R}^{3}$ - filho ASS 3- ir 3- ingerir chicha

'she went with her child to drink chicha (corn liquor)'(Taylor \& Taylor 1966: 13)

(83) o- gwahẽ $\quad$ o- sy $\quad$ Ø- $\quad$-pe

3- chegar $\mathbf{R}^{3}-$ mãe $\mathrm{R}^{1}-$ DAT

'he arrived to/for his mother' (Taylor \& Taylor 1966: 13) 
(84) o- nhonha o- $^{-}$ape $\quad \varnothing$-gwy $\quad$-py o- $^{-}$akã $\quad i^{-} \quad$ xu $\quad$ gwi 3- colocar $\mathbf{R}^{3}$ - casco $\mathbf{R}^{1}$-SOB -LP $\mathbf{R}^{3}$ - cabeça $\mathrm{R}^{2}$ - DIR ABL 'he put his head under his shell away from him' (Taylor \& Taylor 1966: 10)

(85) o- $^{-} \mathrm{i}^{-}$pete $\mathrm{h}^{-}$ovajáry ava ete o- $^{-}$poxíto $\varnothing$ - py 3- $\mathrm{R}^{2}$ - bater $\mathrm{R}^{2}$ cunhado homem GEN $\mathbf{R}^{3}$ - túnica $\mathrm{R}^{1}$ - INSTR 'avaete swiped at his brother-in-law with his tunic' (Taylor \& Taylor 1966: 10)

(86) h- asẽ mba rei ho- 'aypa -ramo $\mathrm{R}^{2}$ - chorar todos debalde $\mathbf{R}^{3}$ - ter.fome -SUBJ 'they howl in vain when they are hungry" (Taylor \& Taylor 1966: 24)

Classe II

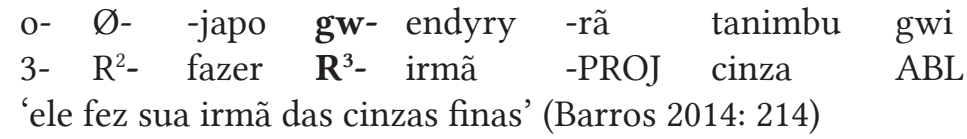

(88) t- úvy o- $\varnothing-$ mbo- tyryry -uka

$\mathrm{R}^{4}$ - pai 3- $\mathrm{R}^{2}$ - CAUS- acompanhar -C.PREP

gw- a'ýry $\varnothing-$ pe jagwa

$\mathbf{R}^{3}$ - filho $\mathrm{R}^{2}$ - $\mathrm{DAT}$ cão

'father made his son drag the dog' (Taylor \& Taylor 1966: 12)

(89) Fábio o- h- ekyi pa gw- ãi Fábio 3- $\mathrm{R}^{2}-$ puxar todos $\mathbf{R}^{3}$ - dente 'Fábio extraiu todos os próprios dentes'

O relacional 4 indica que o possuidor é genérico e humano:

(90) oro- kanhy oro- gwahẽ Ø- óga -py 1.excl- esconder 1.excl- chegar $\mathbf{R}^{4}$ - casa LP 'nós fugimos e chegamos na casa - Barros $(2014,151)$

(91) o- me'ẽ -va'e $\quad$-kwe xe $\quad$-vy João 3- dar -NOM $\quad$-RETR 1 -D.PRON João 'João tinha me dado antes...

mixĩ -mi $\quad \varnothing-$ pohã $\quad$-va'e $\quad$-kwe pouco -ATEN $\mathbf{R}^{4}$ - remédio -NOM -RETR 'um pouquinho de remédio' (Barros 2014: 185) 
(92) o- i- kwaa ava $\mathbf{t}^{-}$ape o- $^{-}$- japo -ha -gwe 3- $\mathrm{R}^{2}$ - saber índio $\mathbf{R}^{4}-$ caminho $3-\mathrm{R}^{2}$ - fazer -NOM -RETR 'o índio sabia o caminho que tinha feito' (Barros 2014: 155)

(93) t- embi- 'u pyhare ve ka'aru -kwe $\mathbf{R}^{4}$ - N.OBJ- comer manhã mais tarde -RETR 'a comida de manhã cedo e do fim da tarde' (Barros 2014: 216)

\subsection{Objeto/posposição}

As posposições constituem uma classe fechada de palavras. Elas sucedem um elemento de natureza nominal, formando com este uma unidade sintática. Recebem flexão relacional, assim como nomes relativos e verbos transitivos. Identificamos em Kaiowá os seguintes temas posposicionais: ehelese; rupi; py; pe; koty ngoty; 'ári; enonde; ndive endive; kupe; e apykwe.

(94) nda ij- a'e ve - i voi xe $\mathbf{r}-$ ehe

NEG $\quad \mathrm{R}^{2}-$ gostar mais $\quad$-NEG mesmo $1 \quad \mathbf{R}^{1}-$ REL

‘eles não gostam mesmo de mim' (Barros 2014: 144)

(95) ha'e h- eko porã -va'e oro- 'e $\mathbf{h}^{-}$ese este R- estar.em.mov bom -NOM 1.excl dizer $\mathbf{R}^{2}-\quad$ REL 'ele tem um bom caráter, dizíamos sobre ele...

o- ho ma -ramo

3- ir COM -SUBJ

quando eles partiram' (Barros 2014: 157)

(98) upéi i- ro’y $\quad$-ramo kyha então $\mathrm{R}^{2}$ - frio -SUBJ rede $-\mathrm{LP}$ 3- pegar $\mathbf{R}^{2}-$ SOB $\quad$-LP 'então quando ficou frio na rede, ele fez um fogo embaixo dela' (Barros 2014: 209)

(99) kunha Ø- pe o- mbo- gwapy ij- akatúa Ø- koty mulher $\mathbf{R}^{1}$ - DAT 3- CAUS- sentar $\mathrm{R}^{2}$ - lado.direito $\mathbf{R}^{1}$ - DIR 'fizeram a mulher sentar ao seu lado direito' (Barros 2014: 145)

(100) ja- ha ve amo Ø- ngoty

1.incl- ir mais aquele $\mathbf{R}^{1-}$ DIR

'vamos mais naquela direção' (Barros 2014: 190)

(101) jakare ogw- era- ha ke' $y^{23} \quad \varnothing_{-}$pe jacaré 3- CC- ir irmão $\mathbf{R}^{1-}$ DAT 'o jacaré levou (com ele) nosso irmão...

${ }^{23}$ Variação de yke'y: t-yke’y 'irmão mais velho de alguém', t-yke’y 'irmão mais velho dele', xe r-yke'y 'meu irmão mais velho', ore r-yke'y 'nosso irmão', Maria r-yke’y 'irmão mais velho de Maria'. 
yvyra r- akã $\varnothing-$ gwy $\varnothing-$ rupi árvore $\mathrm{R}^{1}$ - galho $\mathbf{R}^{1}$ - INESS $\mathbf{R}^{1}$ - PERL por baixo do galho da árvore' (Barros 2014: 198)

(102) $\mathrm{t}$ ere- ho nde $\mathrm{r}$ - ape $\varnothing$ - rupi PERM 2- ir $2 \quad \mathrm{R}^{1}-$ caminho $\mathbf{R}^{1}-$ PERL 'vá pelo teu caminho' (Barros 2014: 209)

(103) ogw- ejy ko yvy Ø- 'ári o- $^{-}$pyta hagwã 3- descer este terra $\mathbf{R}^{\mathbf{1}}$ - LOC 3- ficar PROJ 'desceram para ficarem aqui na terra' (Barros 2014: 155)

(104) o- ike jave monde ho- 'a hi- 'ári 3- entrar quando mundéu 3- cair $\mathbf{R}^{2}$ - SOBRE 'quando ele entra, o mundéu cai em cima dele' (Barros 2014: 160)

(105) mokõi h- emiarirõ o- $^{-} \mathrm{u} \quad \mathrm{o}^{-}$ke $\quad \mathbf{h}^{-}$endive dois $\mathrm{R}^{2}$ - neto 3- vir 3- dormir $\mathbf{R}^{2}-$ ASS 'dois netos dela vinham e dormiam com ela' (Barros 2014: 158)

(106) xe $\varnothing$ - sy $\varnothing$ - ndive a- ju $1 \quad \mathrm{R}^{1}$ - mãe $\mathbf{R}^{1}$ - ASS 1 - vir 'eu vim com minha mãe' (Barros 2014: 211)

(107) nha- nhe- mi yvyra Ø- kupe -py 1.incl- REF- esconder árvore $\mathbf{R}^{1}$ - atrás.de -LP 'nós nos escondemos atrás da árvore' (Barros 2014: 175)

(108) a- ju jevy r- óga $\varnothing-$ py 1- vir de.novo $\mathrm{R}^{1}$ - casa $\mathbf{R}^{1}$ - $\mathrm{LOC}$ 'eu vim de novo para minha casa' (Barros 2014: 196)

(109) i- tuja ma oka r- apykwe $\mathrm{R}^{2}$ - velho COM terreiro $\mathbf{R}^{1}$ - parte.de.trás 'atrás do quintal tudo tinha ficado velho' (Barros 2014: 196)

(110) Paulina $\varnothing$ - pe ogw- ero- 'a ma voi -ramo Paulina $\mathbf{R}^{1}$ - DAT 3- CC- cair COM mesmo -SUBJ 'quando o cavalo derrubou mesmo a Paulina...

xe a- tira h- apykwe $\varnothing$ - koty

1 1- tirar $\quad \mathbf{R}^{2}$ - parte.de.trás $\quad \mathbf{R}^{\mathbf{1}}-$ DIR eu puxei atrás dele' (Barros 2014: 216) 


\subsection{Objeto/Verbo}

O objeto e o verbo transitivo podem constituir uma unidade sintática. Nesse caso, o objeto precede imediatamente o núcleo verbal, e este, por sua vez, recebe o prefixo relacional 1 . Assim como os temas nominais e posposicionais, os temas verbais estão distribuídos em duas classes: Classe I e Classe II. Pertencem à Classe I os temas que se combinam com o alomorfe $\varnothing$ - do prefixo relacional 1 e à Classe II os temas que se combinam com o alomorfe $r$ - do mesmo prefixo:

(119) Maria xe Ø- nupã kwehe

Maria $1 \quad \mathbf{R}^{\mathbf{1}}$ - bater ontem

'Maria me bateu ontem'

(120) Maria xe r- exa kwehe

Maria $1 \quad \mathbf{R}^{\mathbf{1}}$ - ver ontem

'Maria me viu ontem'

A não contiguidade do objeto é marcada por i- nos temas da Classe I e por $h$ - nos temas da Classe II.

(121) a- i- nupã jagwa

1- $\quad \mathbf{R}^{2}-$ bater cachorro

'eu bati no cachorro'

(122) a- h- exa jagwa

1- $\quad \mathbf{R}^{2}$ - ver cachorro

'eu vi o cachorro'

Os temas verbais da classe II, ao se combinarem com o prefixo reflexivo jeou com o recíproco jo-, bloqueiam a ocorrência do relacional 2.

(123) Fábio o- je- hexa

Fábio 3- REF- ver

'Fábio se vê'

(124) nhande ja- jo- hexa

1.incl 1.incl- REC- ver

'Nós nos vemos'

Em alguns temas da Classe I, a marca de não-contiguidade foi reduzida a zero, devido a processos fonológicos, como já mencionamos neste estudo. Isso ocorreu em temas iniciados por $/ j /$ : 
(125) a- Ø- juka $<\mathrm{i}+$ juka

$1 \quad \mathbf{R}^{2-}$ matar

'eu o mato'

(126) a- $\quad$ - $\quad$ japo $<\mathrm{i}+$ apo

$1 \quad \mathbf{R}^{2}-$ fazer

'eu o faço'

(127) a- Ø- japi $<$ i + api

$1 \quad \mathbf{R}^{2}-$ jogar

'eu o jogo/atiro fora'

Os temas transitivados pelo morfema causativo mo- $\sim$ mbo- também apresentam o morfema $\varnothing$ - do relacional 1 para indicar a não contiguidade do objeto:

$$
\begin{array}{lccc}
\text { a- } & \varnothing- & \text { mo- } & \text { sẽ } \\
1- & \mathbf{R}^{2}- & \text { CAUS- } & \text { sair } \\
\text { 'eu o faço } & \text { sair / eu o expulso' }
\end{array}
$$

(129) a- Ø- mbo- gwapy

1- $\quad \mathbf{R}^{2}-\quad$ CAUS sentar

'eu o faço sentar'

O mesmo ocorre com verbos derivados por meio do morfema causativocomitativo:

$$
\begin{array}{llll}
\text { a- } & \varnothing- & \text { r- } & \text { u } \\
1- & \mathbf{R}^{2}- & \text { C.COM } & \text { vir } \\
\text { 'eu o faço vir comigo / eu o trago' }
\end{array}
$$

(131) a- $\varnothing-$ ra- ha

1- $\mathbf{R}^{2}-\quad$ C.COM ir

'eu o faço ir comigo / eu o levo'

Rodrigues (1981) descreve para o Tupinambá um alomorfe do $R^{2}$ - que ocorre apenas com verbos transitivos monossilábicos, jo- e jos-. O primeiro se combina com temas da classe 1 e o segundo com temas da classe 2. Em Kaiowá, as formas cognatas desses morfemas foram reanalisadas como parte da raiz: 
(132) o- $\varnothing-\quad$ joka $\quad$ o- i- $^{-}$yva 3- $\quad \mathbf{R}^{2}-\quad$ rachar 3- $\mathbf{R}^{2}-$ derrubar 'racharam-na e derrubaram-na (a árvore) (Barros 2014: 169)

(133) a- Ø- johéi xe $\varnothing$ - pyta ${ }^{-}$asy 1- $\quad \mathbf{R}^{2}$ - lavar $3 \quad \mathrm{R}^{1}$ - calcanhar $\mathrm{R}^{2}-$ dor 'eu lavo meu calcanhar dolorido (Barros 2014: 169)

(134) nd ere- je jopy -i

NEG 2- REF apertar -NEG

'você não se aperta'

No entanto, em temas transitivos monossilábicos, quando há incorporação do objeto, os mais velhos usam com mais frequência a forma supletiva desses verbos sem o antigo relacional.

$$
\begin{aligned}
& \text { a- je- po héi } \\
& 1 \text { REF- mão lavar } \\
& \text { 'lavo as próprias mãos' }
\end{aligned}
$$

(136) a- je- po johéi 1- REF- mão lavar 'lavo as próprias mãos'

(137) a- nhe- akã héi

1- REF- cabeça lavar 'lavo a própria cabeça'

(138) a- nhe- akã johéi 1 REF- cabeça lavar 'lavo a própria cabeça'

(139) a- je- juru héi 1- REF- boca lavar 'lavo a minha própria boca'

(140) a- je- juru johéi 1- REF- boca lavar 'lavo a minha própria boca'

Isso mostra que esse alomorfe do prefixo $R^{2}$ - foi muito produtivo na língua Kaiowá e que a perda de sua funcionalidade é fato recente. 


\subsection{Temas descritivos}

Com temas nominais descritivos temos as seguintes estruturas ${ }^{24}$ :

Tema da classe 1:

(141) xe Ø- mandua

$1 \quad \mathrm{R}^{1}-$ lembrar

'eu lembro / minha lembrança'

(142) nde Ø- mandua

$2 \quad \mathrm{R}^{1}$ - lembrar

'você lembra / tua lembrança'

(143) ore $\varnothing-$ mandua

1.excl $\mathrm{R}^{1}-\quad$ lembrar

'nossa excl. lembrança'

\section{Tema da Classe II}

$$
\begin{array}{lll}
\text { xe } & \mathrm{r}- & \text { esarái } \\
1 & \mathrm{R}^{1}- & \text { esquecer } \\
\text { 'meu } & \text { esquecimento' }
\end{array}
$$

$$
\begin{array}{lll}
\text { nde } & \mathrm{r}- & \text { esarái } \\
2 & \mathrm{R}^{1}- & \text { esquecer } \\
\text { 'teu } & \text { esquecimento' }
\end{array}
$$

\section{Considerações finais}

Os dados analisados da língua Kaiowá, no âmbito deste estudo, comprovam que: (a) os prefixos relacionais continuam ativos em temas verbais, nominais e posposicionais da língua Kaiowá; (b) o Kaiowá mantém os quatro prefixos relacionais cognatos dos prefixos relacionais identificados por Rodrigues no Tupinambá (1981), a saber: $R^{1}$ - (marca a contiguidade sintática do determinante), $\mathrm{R}^{2}$ (marca a não-contiguidade sintática do determinante), $R^{3}$ -

${ }^{24}$ Cardoso (2008) considera temas dessa natureza como verbos intransitivos inativos, os quais não recebem os prefixos pessoais marcadores de sujeito a- 1, ere- 2, o- 3, oro- 1.excl, ja- 1.incl, em vez disso, o sujeito é representado pelos pronomes pessoais que, nesse tipo de estrutura, segundo a autora, são clíticos pronominais. Rodrigues (1996) defende a ideia de que temas dessa natureza são nomes. Esta é análise que adotamos no presente estudo. 
(marca a correferência do determinante com o sujeito), e $R^{4}$ - (genérico-humano (); (c) houve mudança de temas da Classe Ib para a Classe Ia, permanecendo a alternacia pohã 'remédio' e porahéi 'canto', no entanto a forma mohã e mborahéi é conservada apenas na fala dos mais velhos; (d) ocorreu a eliminação da subclasse IId, pois não há temas em que a indicação do genérico e humano seja feita por meio da elisão da vogal inicial; (e) houve a mudança de classe dos temas da Classe IId, ex. ape 'caminho' para IIa e de temas da classe Ia para IIc, ex. hu'y 'flecha'; a mudança de temas como enonde 'diante.de' da Classe IIa para a Classe IIb; (e) há casos de variação de formas de temas, distribuídas em classes distintas, como úvy úva 'pai' (i-túvy 'pai dele' (classe 1) t-úva 'pai dele' (Classe 2b), embora só os mais jovens tendo preferência pela forma $i$-túva; e (f) existência de vestígios dos alomorfes jo- jos do $R^{2}$-.

\section{Referências}

Barros, E. B. L. de. 2014. Dicionário bilíngue Kaiwá-Português. Dissertação de Mestrado. Três Lagoas-MS: UFMS.

Brand, Jacob. 1993. O confinamento e seu impacto sobre os pai-Kaiowá. Dissertação de Mestrado. Porto Alegre: PUC.

2004. Os complexos caminhos da luta pela terra entre os Kaiowá e Guarani no MS. Tellus, Campo Grande, v. 6, n. 1, p. 137-150.

Bridgeman, L. I. A note on stress in Kaiwá. 1960. Arquivo Linguistico no 225. BrasiliaDF: Summer Institute of Linguistic.

1961. Kaiwa (Guarani) phonology. International Journal of American Linguistics, 27, p. 329-334.

1981. O parágrafo na fala dos Kaiwá-Guarani. Brasilia-DF: Summer Institute of Linguistics.

2001. Dicas sobre a língua Kaiwá. Sociedade Internacional de Linguística - SIL.

Cabral, A. S. A. C. 2001. Flexão Relacional na Família Tupí-Guaraní. Boletim ABRALIN, 25: 233-62.

Cardoso, V. F. 2001. Um estudo de categorias sintagmáticas da língua Kaiowál Guarani. Dissertação de Mestrado. Mato Grosso do Sul: UFMS.

2005a. Estudo Preliminar da Morfossintaxe Verbal da Língua Kaiowá-Guarani. Estudos Lingüísticos GEL, http://gel.org.br/4publica-est, v. XXXIV, p. 714-719.

. 2005. Categorias Sintagmáticas Lexicais da Língua Kaiowá-Guarani. In: BARONAS, R. L. (Org.). Identidade Cultural e Linguagem. Campinas - Caceres: Pontes e Unemat editora, p. 83-93.

. 2006. Marcadores de Pessoa em Kaiowá/Guarani. Ave Palavra (UNEMAT), v. 1, p. $15-30$.

2008a. Aspectos Morfossintáticos da Língua Kaiowá (Guarani). Tese de Doutorado. Campinas, SP: Unicamp. 
. 2008b. Negação em Kaiowá (Guarani). Ave Palavra (UNEMAT), v. 10, p. 1-7. 2009. Sistematização da Fonologia Kaiowá: nasalização e/ou oralização. Sínteses (UNICAMP. Online), v. vol.14, p. 31-72.

. 2010a. Inversión semántica en Kaiowá. In: Lengua y Literatura Mapuche, v. 14 , p. 20-32.

. 2010b. O idioma guarani e suas variações. IHU On-Line (UNISINOS. Impresso), v. x, p. 25-26;

. 2010c. A língua guarani e o português no Brasil. In: NOLL, Volker; Wolf Dietrich. (Org.). O português e o tupi no Brasil. 1ed.São Paulo -SP: Editora Contexto, v., p. 155-166.

. 2011. In: Oliveira, D. P. de. (Org.). Estudos linguísticos - gramática e variação. Campo Grande-MS: Ed. UFMS, v. 1, p. 75-90.

2013. Sujeito bilíngue em situação de contato: o português e o guarani. In: Maluf-Souza, O.; Silva, V.; almeida, E. de; Bisinoto, L. S. J. B. (Orgs.). Discurso, Sujeito e memória. 1ed.Campinas-SP: Pontes, v. 0, p. 21-31.

. 2014a. Contato de línguas: o português e o kaiowá/guarani. III Encuentro de Lenguas Indigenas Americanas, v. 1, p. 79-90.

. 2014b. O português de contato dos Kaiowá (Guarani). In: Ferreira, R. V.; Sá Amado, R. de \& Cristino, B. P. (Orgs.). Português Indígena: novas reflexões. München - Alemanha: LINCOM Studies in Romance Linguistics, v. 1, p. 50-70.

. 2014c. A variedade kaiowá (guarani) e seu contexto multilíngue. In: Pria, A. D.; Moralis, E. G.; Cardoso-Carvalho, V. F.; carvalho, G. A. de. (Org.). Linguagem e línguas: invariância e variação. Campinas-SP: Pontes, v. 1, p. 59-70.

. 2014d. Contato de língua o português e o Kaiowá (guarani). In: Malvestitti, M.; Dreidemie, P. (Orgs.). III Encuentro de Lenguas Indigenas Americanas. Libro de Actas. Bariloche-AR: Viedma, v. 1, p. 79-90.

. 2015. Descrição Gramatical do Kaiowá (Guarani). 1. ed. (Reino Unido e Alemanha): NEA - Novas Edições Acadêmicas, v.1.

Cardoso, V. F.; Moralis, E. G. , 2012. Influência linguística e situação de contato entre o português e o Kaiowá (Guarani). Abralin Curitiba 2011, v. 1, p. 1-12.

Cavalcante, Thiago Leandro Vieira. 2013. Colonialismo, território e territorialidade: a luta pela terra dos Guarani e Kaiowa em Mato Grosso do Sul. Tese de Doutorado. Assis-SP: UNESP.

CENSO DEMOGRÁFICO. 2010. Características gerais dos indígenas. Rio de Janeiro: IBGE, pp. 1-254.

Chamorro, G. História Kaiowa: Das Origens aos Desafios Contemporâneos. 2015. São Bernardo do Campo: Nhanduti Editora.

Concianza. Fabio. et al. Vocabulário escolar bilíngue Kaiowá e Português. 2015. Dourados, MS. UFGD, $116 \mathrm{p}$.

Eremites de Oliveira, J.; Pereira, L. M.. 2009. Ñande Ru Marangatu. Laudo antropológico 
e histórico sobre uma terra kaiowa na fronteira do Brasil com o Paraguai, município de Antônio João, Mato Grosso do Sul. Dourados: Editora UFGD.

Harrison, C. H. e J. M. 1958. Kaiwá phonemes and syllable struture. Summer Institute of Linguistics.

. 1971. Nasalization in Kaiwá. In: D. Bendor-Samuel (ed.) Tupi Studies 1, University of Oklahoma, Norman, p. 15-20.

Lutti, A.C. , 2009. Acampamentos indígenas e ocupações: novas modalidades de organização e territorialização entre os Guarani e Kaiowá no município de Dourados - MS: (1990-2009). Dissertação de Mestrado. Dourados: UFGD.

Lima, M. H. F. 2012. Quando a terra indígena é um acampamento de baracos: situações vivenciadas por índios Guarani Kaiowa e Ñandeva em Mato Grosso do Sul. In: XI Encontro de História de Mato Grosso do Sul, 2012, Campo Grande. XI Encontro...,

Maciel, N. A. História dos Kaiowa da Aldeia Panambizinho da década de 1920 aos dias atuais. 2005. Dissertação (Mestrado em História). Dourados: Universidade Federal de Mato Grosso do Sul.

Martins, A. M. S. A., 2014. A presença do prefixo correferencial de terceira pessoa em uma variedade da língua Kaiowá. In: PRIA, Albano Dalla et al. (Orgs.). Linguagem e línguas: invariância e variação. Campinas-SP: Pontes.

Pacheco, R.A.S. 2004. Mobilidades guarani Kaiowá e Nandeva e a (re)construção de territórios (1978-2003): novas perspectivas para o direito indígena. Dissertação (Mestrado em História). Dourados: UFMS.

Pereira, Levi Marques. 2003. O movimento étnico-social pela demarcação das terras guarani em MS. Tellus, Campo Grande, v. 3, n. 4, p. 137-145, abr.

. 2006. Assentamentos e formas organizacionais dos Kaiowa atuais: o caso dos índios corredor. In: Tellus, v. 6, n. 10., p. 9-81.

. 2010. Demarcação de terras kaiowa e guarani em MS: ocupação tradicional, reordenamentos organizacionais e gestão territorial. In: Tellus, ano 10, n. 18. Campo Grande, 115-137.

.2015. A Reserva Indígena de Dourados: a atuação do Estado brasileiro e o surgimento de figurações indígenas multiétnicas. In: CHAMORRO, Graciela \& COMBÈS, Isabelle. Povos indígenas em Mato Grosso do Sul: história, cultura e transformações sociais. Dourados-MS: Ed. UFGD, pp. 781-794.

Pike, K. L. Language. In: Relation to a Unified Theory of the Structure of Human Behavior. 1954. Summer Institute of Linguistics, Santa Ana, Cal. Vol. I.

Rodrigues, A. D. Estrutura do Tupinambá, 1981, ms. Publicado em: Cabral, A.S.A.C.; Rodrigues, A.D.; Duarte, F.B. Línguas e Culturas Tupí. 2010. Campinas, SP: Curt Nimuendajú; Brasília: LALI/UnB, pp. 11-42.

. 1984-85. Relações internas na família lingüística Tupí-Guaraní. Revista de Antropologia, 27/28, p. 33-53. São Paulo.

. 2011. Argumento e Predicado em Tupinambá. Boletim da ABRALIN, n. 19, 1996, p. 57-66. Rebuplicado na Revista de Linguística Antropológica, v. 3, 
n.1 (Jul. 2011) - Brasília: Laboratório de Línguas Indígenas, Instituto de Letras, Universidade de Brasília, p. 93-102. Aryon Dall'Igna Rodrigues (editor), Ana Suelly Arruda Câmara Cabral (co-editora).

Silva, C. A. do. N. 2011. O uso de neologismos por empréstimo em Kaiwá: um estudo preliminar da versão do Novo Testamento Bíblico. Dissertação de Mestrado. Três Lagoas: UFMS.

Silva, M. A. da. O Movimento dos Guarani e Kaiowá de reocupação e recuperação de seus territórios em Mato Grosso do Sul e a participação do Conselho Indigenista Missionário. 2010 [1966]. Dissertação (Mestrado em História). Dourados: UFMS, 2005.

Taylor, John Michael and Taylor, Audrey Helen. Statement of Kaiwá Grammar from Clause to Morpheme Level. Associação Internacional de Linguística - SIL Brasil, Anápolis-GO.

. Gramática Pedagógica da Língua Kaiowá. SIL, s/d.

Vietta, K. Histórias sobre terras e xamãs kaiowa: territorialidade e organização social na perspectiva dos Kaiowa de Panambizinho (Dourados, MS) após 70 anos de exploração e povoamento não indígena da faixa da fronteira entre o Brasil e o Paraguai. 2007. Tese (Doutorado em Antropologia Social). São Paulo: USP. 